\title{
Salvage of a Finger Near Total Avulsion Amputation: A Simpler Alternative Technique
}

\author{
Smriti Bhushan ${ }^{1}$ Ravikiran Naalla ${ }^{1} \quad$ Maneesh Singhal ${ }^{1}$
}

\author{
${ }^{1}$ Department of Plastic Reconstructive and Burns Surgery, Plastic \\ Surgery Office, All India Institute of Medical Sciences, New Delhi, \\ India
}

Indian J Plast Surg 2020;53:162-163

Crush avulsion amputation of fingers are the most severe injuries due to the involvement of rotational, pulling, and crushing forces. ${ }^{1}$ Sometimes, it is challenging to assess the extent of damage to the neurovascular structures. However, it was proven beyond doubt that salvage of avulsion amputations results in better functional outcomes. ${ }^{2}$

We present a 23-year-old woman with a history of washing machine dryer injury to the right index finger. On examination, there was near total amputation of the index finger at the level of middle phalanx with a longitudinal split. Soft tissue was crushed along with all the neurovascular structures. The finger was just attached with FDP tendon and a small segment of crushed dorsal skin. There was an asymmetrical skin laceration (-Fig. 1).

The conventional way of treating avulsion amputations include skeletal fixation with or without shortening, followed by repair of tendon and neurovascular structures. ${ }^{3}$ In this technique, the skin bridge connecting the proximal and distal finger stumps may carry a healthy artery or vein and is preserved. Successful revascularization of these fingers may require vein grafts to bridge the segmental vessel defects, and flaps to cover the critical soft tissue defects. ${ }^{3}$

In our patient, the digit was avascular (near total amputation), and the vessels in the crushed skin segments were not reliable. In this clinical situation, we found that it is easier to divide the existing attachment between the distal and proximal
Address for correspondence Ravikiran Naalla, MCh, Department of Plastic Reconstructive and Burns Surgery, Plastic surgery office, $5^{\text {th }}$ floor, Teaching Block, All India Institute of Medical Sciences, New Delhi 110029, India (e-mail: ravi_2488@yahoo.co.in).
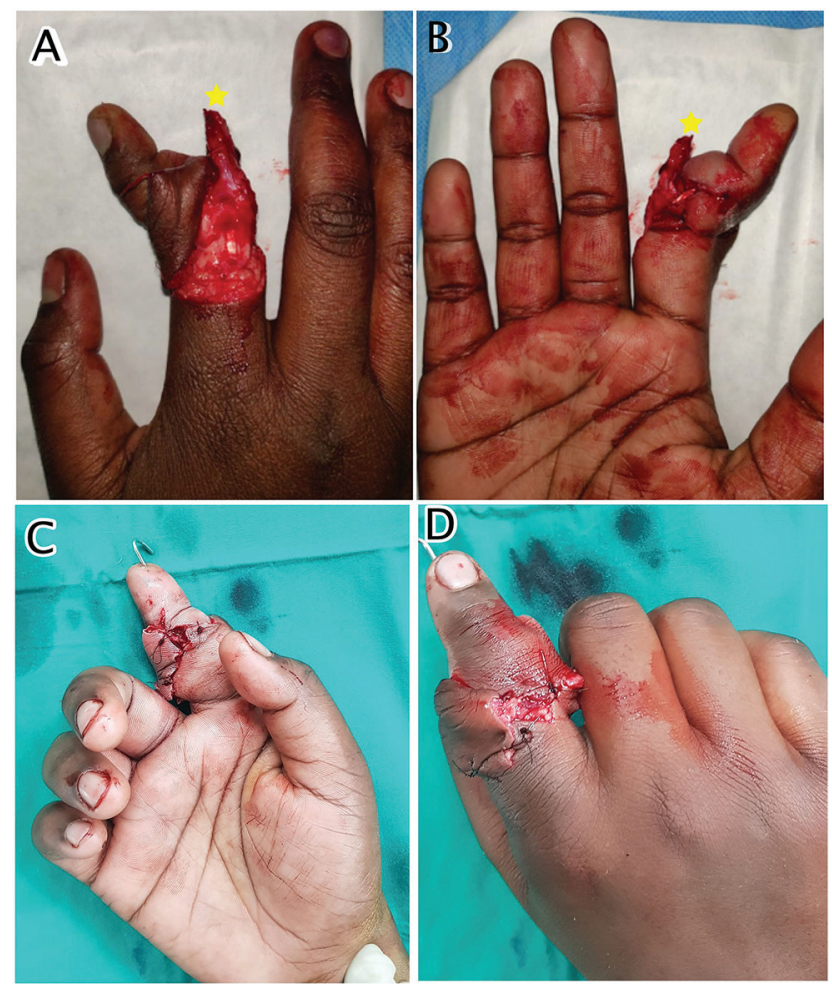

Fig. 1 Image showing avulsion amputation of right index finger (star indicating split middle phalanx) (A, B), and after successful replantation (C, D). ISSN 0970-0358.
License terms

(ㅇ) (1) $\ominus \circledast$ 
finger stumps, to complete the amputation of the digit and then perform a replantation. By this conversion, the bone shortening is less cumbersome, and judgment of multisegmental vessel damage is easier. A two-team approach for simultaneous dissection and tagging of proximal and distal stumps is feasible. Additionally, we can cover the critical structures with skin flaps in a more versatile manner. We performed $1.5 \mathrm{~cm}$ bone shortening and repair of a single digital artery and two dorsal veins. The asymmetrical skin flaps were tailored to cover the vessels. At 2 month follow-up the patient had a satisfactory outcome (-Fig. 2). Flexor digitorum profundus repair would have further improved the outcome.
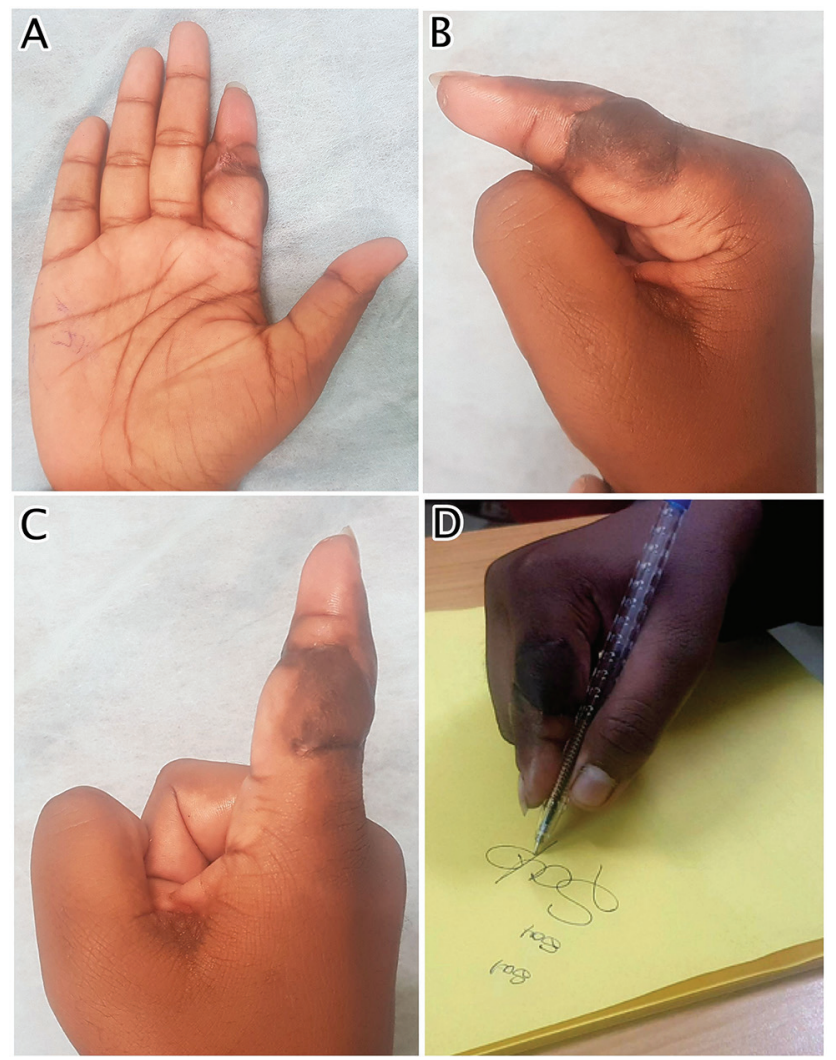

Fig. 2 Image showing satisfactory result (A-C), and patients ability to write using the digit (D).
To conclude, in selected severe crush avulsion near -total amputations where there are no critical tissue attachments, converting into total amputation and replantation is a simpler alternative technique.

\section{Financial Disclosures}

Nil.

\section{Details of Earlier Presentation}

Nil.

Authors confirm to the declaration of Helsinki.

\section{Conflict of Interest}

None.

\section{References}

1 Molski M. Replantation of fingers and hands after avulsion and crush injuries. J Plast Reconstr Aesthet Surg 2007;60(7):748-754

2 Sears ED, Chung KC. Replantation of finger avulsion injuries: a systematic review of survival and functional outcomes. J Hand Surg Am 2011;36(4):686-694

3 Sabapathy R, Venkatramani H, Bharathi R, Sebastin SJ. Replantation of ring avulsion amputations. Indian J Plast Surg 2003;36(2):76-83 